\title{
Endoscopic retrieval of a surgical gauze from the right colon
}

\author{
J. B. Gornals-Soler, T. Lobatón-Ortega, F. Rodríguez-Moranta and J. Miquel-Collell \\ Unidad de Endoscopia. Servicio Aparato Digestivo. Hospital Universitari de Bellvitge. Barcelona, Spain
}

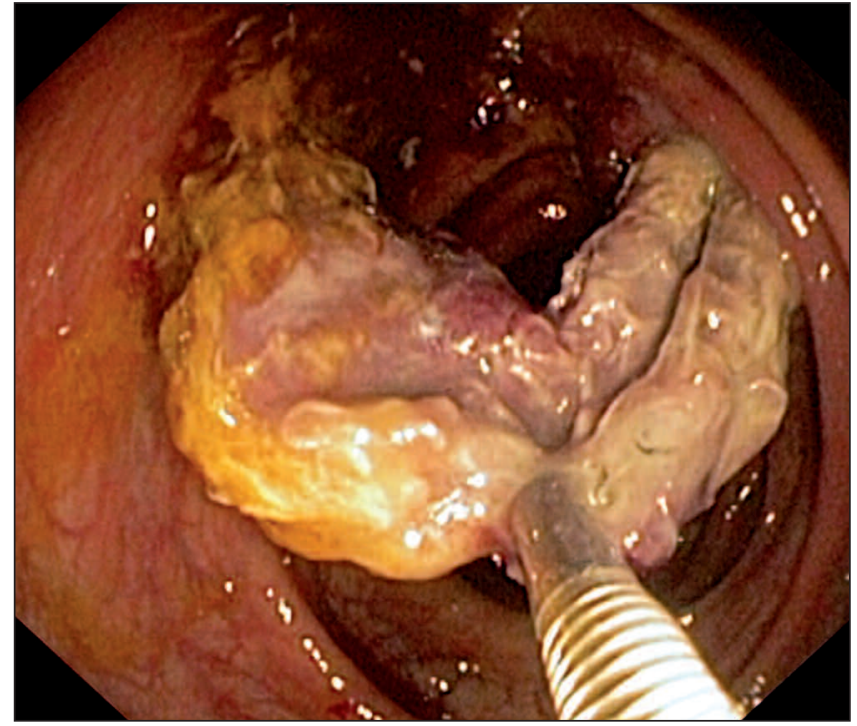

Fig. 1. Endoscopic retrieval with foreign body grasping forceps, from the right colon.

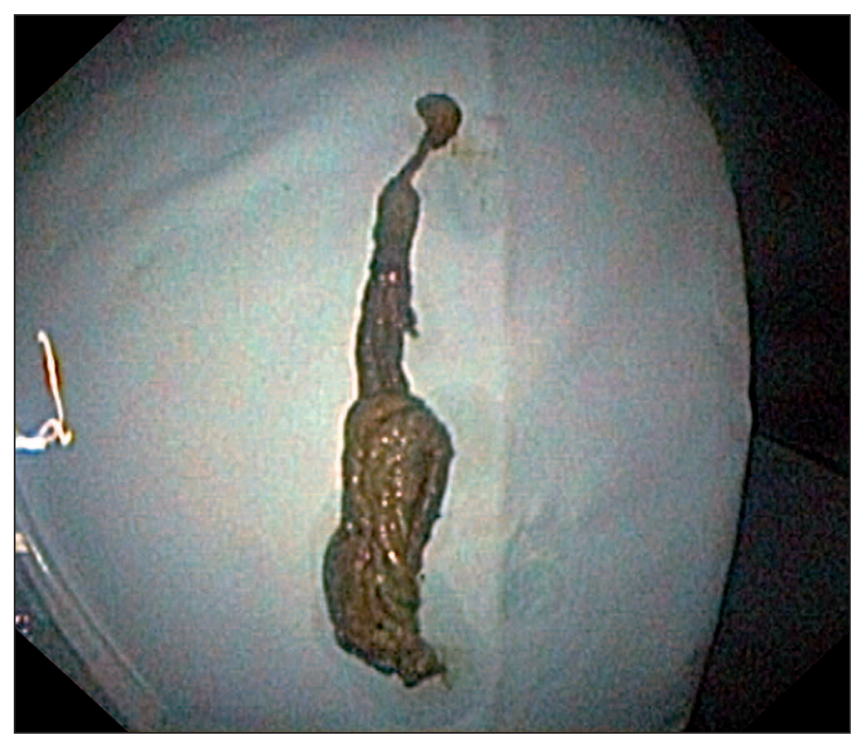

Fig. 3. Image of surgical gaze after the endoscopic retrieval. Total length: $60 \mathrm{~cm}$.

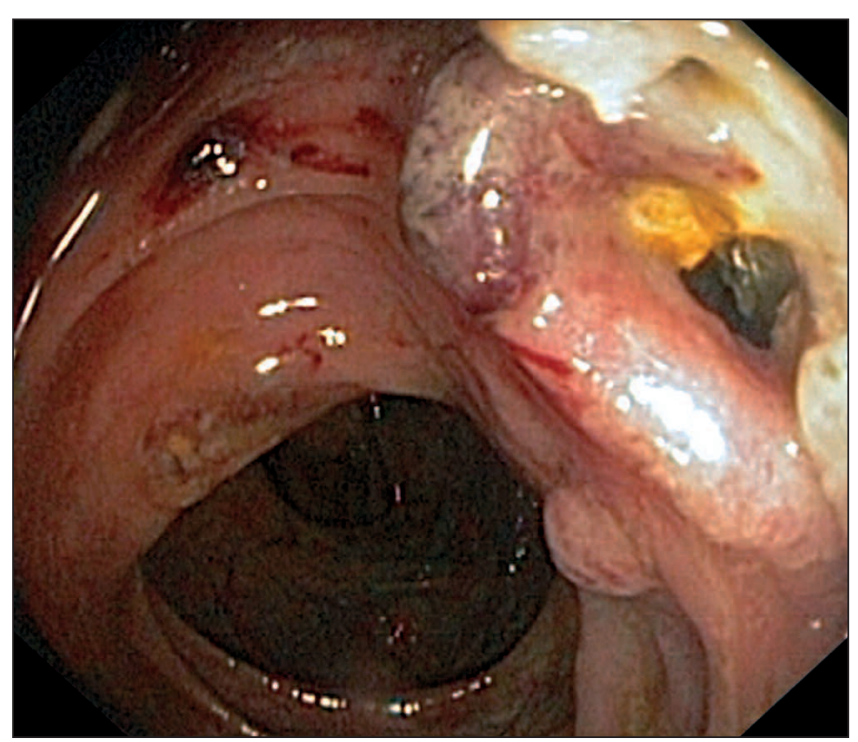

Fig. 2. Image of fistulous orifice in the colonic wall, after the endoscopic retrieval.

A 33-year-old man, who had been operated on a congenital bridle 14 years ago, was admitted to our hospital for evaluation of a 3 month recurrent abdominal pain. CT scan and colonoscopy were performed in another medical centre, in which a chronic inflammatory process surrounding a foreign body was described in the right colon. He was referred to our endoscopy unit, as a tertiary reference hospital, in order to evaluate its extraction. During the endoscopic procedure was visualized a surgical gauze wrapped to an inflammatory intestinal mucosa (with edema and friability) and externalized to the colon lumen (Fig. 1.). Using an endoscopic grasping forceps it was slowly removed until its complete extraction, with a $60 \mathrm{~cm}$ total length (Fig. 2.). It revealed a fistulous orifice (Fig. 3) which was communicated with a cavity, without any evidence of active haemorrhage. He had a good clinical evolution and outcome; no more episodes of abdominal pain were referred. A control CT scan was performed 3 months later, which showed slight residual inflammatory changes. It is not unusual to find surgical foreign bodies after a surgical intervention $(1,2)$. They are usually symptomatic; presenting 
as abscesses, acute or chronic abdominal pain or haemorrhage, due to blood vessels or intestinal wall's erosion. Normally, the therapeutic approach consists in another surgical intervention in order to remove the foreign body (3). In our particular case, symptoms revealed 14 years after the surgical intervention. In our opinion, it is striking the natural evolution of the foreign body to show its way out to the intestinal lumen. In this case, the endoscopic procedure avoided surgery by helping the gauze's extraction.

\section{REFERENCES}

1. Cipolletta L, Bianco MA, Rotondano G, Prisco A, Catalano M, Gatto A, Carlomagno P. Endoscopic retrieval of a surgical gauze from the common bile duct. Ital J Gastroenterol Hepatol 1997; 29(1): 58-61.

2. Ibrahim IM. Retained surgical sponge. Surg Endosc 1995; 9(6): 709-10.

3. Childers JM, Caplinger P. Laparoscopic retrieval of a retained surgical sponge: a case report. Surg Laparosc Endosc 1993; 3(2): 135-8. 